\title{
Intra-Articular Injections of Autologous Conditioned Serum to Treat Pain from Meniscal Lesions
}

\section{(ㄷ)(ㄱ)(응}

\author{
Author \\ Rudolf Strümper
}

\author{
Affiliation \\ Privatpraxis Orthopädie im Rheinauhafen, Cologne, \\ Germany
}

Key words

osteoarthritis, intra-articular, ACS, meniscus, biologic, surgery

\author{
Bibliography \\ DOI https://doi.org/10.1055/s-0043-118625 \\ (c) Georg Thieme Verlag KG Stuttgart · New York \\ ISSN 2367-1890

\section{Correspondence} \\ Rudolf Strümper \\ Privatpraxis Orthopädie im Rheinauhafen \\ Im Zollhafen 6 \\ 50678 Köln \\ Germany \\ info@orthopaede-koeln.de
}

Sports Medicine International Open 2017; 1: E200-E205

\begin{abstract}
Routine use of biological therapies is in its early stages. Techniques involve stem cells, platelet preparations, recombinant growth factors and autologous conditioned serum, often combined with surgery. The objective of this case analysis was to document effects of intra-articular autologous conditioned serum injections in outpatients with knee pain associated with meniscal defects. Autologous conditioned serum was prepared from patients' blood by centrifugal separation from cellular components using a specialized device (EOT ${ }^{\circledR} I I$, Orthokine). Outpatients ( $n=47)$ with heterogeneous knee meniscus lesions (76.6\% traumatic knee injury) were injected once weekly (average 5.2 applications). Average age was 48.6 years (range 21-79). Oxford Knee Score and structural changes with the MRI Boston Leeds Osteoarthritis Knee Score were documented at baseline and 6 months. All analyses were performed retrospectively. In $83 \%$ patients, surgery was avoided during the 6-month observation period. Oxford Knee Score improved significantly from 29.1-44.3 $(p<0.001$; best possible score $=48)$. Structural findings on MRI, measured by Boston Leeds Osteoarthritis Knee Score, showed significant improvement at 6 months $(0.82-0.71, p<0.001)$. This retrospective study implies that intra-articular autologous conditioned serum injection may be an effective treatment option for knee pain associated with meniscal lesions. Controlled studies of autologous conditioned serum treatment for meniscal lesions are advocated.
\end{abstract}

\section{Introduction}

Meniscal lesions, depending on their severity and location, sometimes heal spontaneously or may remain asymptomatic. Osteoarthritis (OA) is frequently associated with both symptomatic and asymptomatic meniscal defects [16]. Treatment of meniscal tears by surgical interventions, including resection, refixation/suturing, scaffold implants and allografts, is the clinical standard; however, there is growing concern that arthroscopic meniscus and/or OA surgical treatment may not be indicated in a substantial subset of patients [27-29, 36, 40]. The recent Osteoarthritis Research Society International (OARSI) guidelines recommend more critical application of surgery [34].

The combination of surgery with augmentation procedures has been proposed to improve clinical outcomes, however, only few controlled clinical studies with biological augmentation techniques for the purpose of improving clinical signs of meniscal injuries have been performed [42]. Such augmentation procedures (experimental and clinical) include recombinant growth factors, platelet concentrates (e. g., platelet-rich plasma), stem cell injections and scaffolds.

Intra-articular injections of autologous conditioned serum (ACS; Orthokine ${ }^{\circledR}$ ) are a therapy for symptomatic osteoarthritic knees and has been in use for $>10$ years [43]. ACS contains autologous components derived solely from the patient's blood and, because ACS is cell-free, it differs fundamentally from platelets or platelet lysate preparations, which contain cells or cell fragments. Elevated concentrations of cytokines and growth factors have been reported with ACS treatment $[43,44]$. 
- Table 1 Characteristics of patients documented in this report.

\begin{tabular}{|c|c|c|}
\hline \multicolumn{2}{|l|}{ Characteristic } & \multirow{2}{*}{$\begin{array}{c}\begin{array}{c}\text { Patients } \\
(\mathbf{N}=\mathbf{4 7})\end{array} \\
\text { (n [\%] unless otherwise stated) } \\
32(68.1)\end{array}$} \\
\hline Gender & Male & \\
\hline & Female & 15 (31.9) \\
\hline Age, years & Mean (range) & $49.4(21-83)$ \\
\hline \multirow{3}{*}{$\begin{array}{l}\text { Duration of } \\
\text { symptoms, } \\
\text { weeks }\end{array}$} & $<4$ & $26(55.3)$ \\
\hline & $\geq 4$ & $15(31.9)$ \\
\hline & Unclear & $6(12.8)$ \\
\hline \multirow[t]{3}{*}{ Surgery } & No & $39(83.0)$ \\
\hline & Yes & $5(10.6)$ \\
\hline & Unclear & $3(6.4)$ \\
\hline \multirow[t]{3}{*}{ Knee affected } & Left & $18(38.3)$ \\
\hline & Right & $26(55.3)$ \\
\hline & Both & $3(6.4)$ \\
\hline \multirow{2}{*}{$\begin{array}{l}\text { Retropatellar } \\
\text { cartilage defect }\end{array}$} & Yes & $42(89.4)$ \\
\hline & No & $5(10.6)$ \\
\hline \multirow[t]{3}{*}{ Trauma } & Yes & $36(76.6)$ \\
\hline & No & $9(19.1)$ \\
\hline & Unclear & $2(4.3)$ \\
\hline
\end{tabular}

Examination of patients with knee pain routinely includes the Oxford Knee Score (OKS) and magnetic resonance imaging (MRI), and MRI often reveals that patients have meniscal lesions, suggesting a retrospective analysis of clinical outcomes in patients receiving knee injections with ACS in the presence of meniscal lesions. The aim of this report was therefore to retrospectively describe a series of cases regarding the clinical effects of intra-articular ACS injections in patients presenting with knee pain associated with MRI-confirmed meniscal defects.

\section{Methods}

\section{Patients and ethical procedures}

Outpatients presenting at the author's private practice with knee pain, a diagnosis of meniscal lesions and who had undergone ACS treatment were included in this retrospective analysis. Data was obtained in compliance with German law and the Declaration of Helsinki, and an ethical committee was consulted for this retrospective study $[1,4]$. Patient anonymity has been carefully protected and data analysis was performed with prior informed consent. This study meets the ethical standards of the journal [25].

\section{ACS}

ACS was prepared with venous blood drawn using the Orthokine device (EOT ${ }^{\circledR}$ II-syringe, Orthogen Lab Services, Germany), which contains glass beads. Patients' blood was incubated in the device for $6 \mathrm{~h}$ at $37^{\circ} \mathrm{C}$. The conditioned, cell-free serum was then recovered by centrifugation and injected into the patient at weekly intervals $[18,43]$.

\section{Data generation}

All patients were routinely examined clinically by MRI and the selfadministered Oxford Knee Score (OKS) questionnaire, which consists of 12 questions [2]. The answers are scored from 0-4 (range from 0-48; worst-best). The recommended scoring system for OKS includes a sub-analysis for a functional score and a pain score [3]. The functional subscore consists of OKS questions 2, 3, 7, 11, 12 (highest possible summed score of 20). Examples for the questions for the functional subscore included 'Could you kneel down and get up again afterwards?', 'Could you do household shopping on your own?', and 'Could you walk down a flight of stairs?'. The OKS pain subscore consists of OKS questions 1, 4, 5, 6, 8, 9, 10 (highest possible summed score of 28), examples of which are 'How would you describe the pain you usually have in your knee?', 'For how long are you able to walk before the pain in your knee becomes severe?', and 'How much has pain from your knee interfered with your usual work (including housework)?' [2]. OKS questionnaires were completed before start and again after 6 months of treatment. Data of patients diagnosed with meniscal defect were selected for analysis. For analysis, subscores were standardized from $0-100$ by multiplying OKS function by 5 and multiplying OKS pain by 3.57 [3].

MRIs were retrospectively evaluated by an independent radiologist using the Boston Leeds Osteoarthritis Knee Score (BLOKS) [19, 32]. In addition, patients were asked for a subjective evaluation of pain and function, and responses were classified as pain free, mostly pain free, undecided, dissatisfied/unchanged, no/unclear information (for pain); fully functional, mostly functional, improved, unclear information (for function).

\section{Statistics}

Data were tabulated using MS Excel, which was also used to produce basic statistics and graphs. Based on the data for all patients before and after treatment, paired t-tests (2-sided) and effect sizes with $95 \%$ confidence intervals $(\mathrm{Cl})$ were computed using programs written in Visual Basic for Applications by S. Cleveland. The effect size (Cohen's d) is a dimensionless measure of change due to an intervention and is independent of sample size. It is computed as the difference between pre- and post- treatment, divided by the common standard deviation of these groups. Cohen's $d$ is expressed as small (0.2-0.5), medium (0.5-0.8), large (0.8-1.2), very large $(1.2-2.0)[12]$.

\section{Results}

A total of 47 outpatients (male/female 32/15; mean age 49.4 years [range 21-83]) with knee pain, and diagnosed with meniscal lesions, were included in this analysis ( $\triangleright$ Table 1 ). Patients presented over a period of 4 years. All patients reported knee pain (left/right/both 18/26/3) of diverse etiology (9 with trauma, 36 without trauma, 2 unclear) and duration ( 1 day-> 1 year). $89 \%$ of selected patients showed retropatellar cartilage defects ( $\triangleright$ Table 1$)$. The mean total number of weekly injections with $2 \mathrm{~mL} \mathrm{ACS}$ each was 5.2 (range 3-8), and 42 patients had a femoropatellar cartilage defect. Five patients requested meniscal surgery $(10.6 \%)$ and 3 patients $(6.4 \%)$ were lost to follow-up. The remaining 39 patients ( $83 \%$ ) completed the OKS 
- Table 2 OKS and BLOKS at baseline and after 6 months of ACS treatment.

\begin{tabular}{|c|c|c|c|c|c|c|c|c|}
\hline & \multicolumn{4}{|c|}{ Summed OKS Score } & \multicolumn{4}{|c|}{ BLOKS } \\
\hline & $\begin{array}{c}\text { Baseline } \\
n=39\end{array}$ & $\begin{array}{c}6 \text { months } \\
n=39\end{array}$ & p-value & $\begin{array}{l}\text { Effect } \\
\text { size d }\end{array}$ & Baseline $n=40$ & 6 months $n=40$ & p-value & $\begin{array}{l}\text { Effect } \\
\text { size d }\end{array}$ \\
\hline Mean (SD) & $29.2(9.1)$ & $44.3(4.3)$ & $<0.001$ & 2.13 & $0.81(0.35)$ & $0.71(0.39)$ & $<0.001$ & 0.28 \\
\hline $\begin{array}{l}\text { Median } \\
\text { (min, max) }\end{array}$ & $30(11,47)$ & $46(31,48)$ & - & - & $0.83(0.17,1.67)$ & $0.67(0,1.67)$ & - & - \\
\hline
\end{tabular}

ACS: autologous conditioned serum; BLOKS: Boston Leeds Osteoarthritis Knee Score; OKS: Oxford Knee Score; SD: standard deviation

The OKS score consists of 12 questions for evaluation of functional and pain symptoms, each scored out of 4 . The best possible score is 48 . All OKS questions are answered according to severity grade: None [4], Very mild [3], Mild [2], Moderate [1], Severe [0]

- Table 3 Function and pain OKS subscores at baseline and after 6 months of ACS treatment.

\begin{tabular}{|c|c|c|c|c|c|c|c|c|}
\hline & \multicolumn{4}{|c|}{ OKS Function Score * } & \multicolumn{4}{|c|}{ OKS Pain Score * } \\
\hline & Baseline $\mathbf{n}=39$ & 6 months $n=39$ & p-value & d & Baseline $n=39$ & 6 months $n=39$ & p-value & d \\
\hline Mean (SD) & $65.4(18.7)$ & $92.6(10.1)$ & $<0.001$ & 1.81 & $57.1(20.8)$ & $92.0(8.5)$ & $<0.001$ & 2.20 \\
\hline $\begin{array}{l}\text { Median } \\
(\min , \max )\end{array}$ & $65(35,100)$ & $95(60,100)$ & - & - & $60.7(10.7,96.4)$ & $96.4(67.9,100)$ & - & - \\
\hline \multicolumn{9}{|c|}{ ACS: autologous conditioned serum; OKS: Oxford Knee Score; SD: standard deviation } \\
\hline \multicolumn{9}{|c|}{ All OKS questions are answered according to grade: None [4], Very mild [3], Mild [2], Moderate [1], Severe [0] } \\
\hline \multicolumn{9}{|c|}{$\begin{array}{l}\text { The OKS functional subscore consists of questions } 2,3,7,11,12 \text {; highest possible score }=20 \text {. The OKS pain subscore consists of questions } 1,4,5,6 \text {, } \\
8,9,10 \text {; highest possible score }=28\end{array}$} \\
\hline \multicolumn{9}{|c|}{$\begin{array}{l}\text { * Normalized: Both pain and function subscores were normalized to } 0-100(0=\text { worst, } 100=\text { best }) \text { by multiplying OKS function by } 5 \text { and multiplying } \\
\text { OLS pain by } 3.57\end{array}$} \\
\hline
\end{tabular}

before and after 6 months of ACS treatment. The mean summed OKS score (SD) at baseline was 29.2 (9.1), increasing significantly to 44.3 (4.3) after 6 months of ACS treatment (34\%, p<0.001). Cohen's $d$ was very large $(2.1$ [ $95 \% \mathrm{Cl} 1.4-2.8])$ ( $>$ Table 2$)$.

The OKS functional subscore increased from $65.4 \pm 18.7$ to $92.6 \pm 10.1$ (29\%, p<0.001), Cohen's d 1.81. OKS pain subscore increased from $57.1 \pm 20.8$ to $92.0 \pm 8.5$ (38\%, p<0.001), Cohen's d 2.20 ( $>$ Table 3).

MRI BLOKS score was available for 40 patients both at baseline and after 6 months of treatment. Of these patients, 17 (49\%) had improved scores at 6 months, 17 were unchanged, and 1 patient had a worse score. Overall, the mean score decreased from 0.81 to 0.71 ( $p<0.001$, paired t-test), but with a small Cohen's $d$ of 0.28 (95\% Cl 0.17-0.39) ( Table 2).

Subjective pain and function evaluation was not available for all patients. Of the available statements, 27/47 reported being painfree and mostly pain-free, and $31 / 39$ reported being fully functional and mostly functional ( $\triangleright$ Table 4 ).

\section{Discussion}

Meniscal abnormalities in asymptomatic patients have been previously described [30]. Although a long-term correlation between meniscal lesions and cartilage degeneration, with and without surgical intervention, appears established $[17,26]$, surgical intervention for meniscal lesions has been under critical review for some time [27-29, 36, 38, 40]. Publications speculating on the potential of biological augmentation of meniscus therapy have popularized less invasive procedures, and research on biological therapy for meniscal lesions has been performed by several groups. Approaches include recombinant growth factors, stem cells of different origin
- Table 4 Patients' subjective evaluation of pain and function.

\begin{tabular}{|l|l|c|}
\hline Evaluation & \multicolumn{1}{|c|}{ Statement } & Patients (n [\%]) \\
\hline \multirow{4}{*}{ Pain } & Statement available & $\mathbf{4 7}$ \\
\cline { 2 - 3 } & Pain-free & $22(46.8)$ \\
\cline { 2 - 3 } & Mostly pain-free & $5(10.6)$ \\
\cline { 2 - 3 } & Undecided & $6(12.8)$ \\
\cline { 2 - 3 } & Dissatisfied/unchanged & $7(14.9)$ \\
\cline { 2 - 3 } & No information & $7(14.9)$ \\
\hline \multirow{5}{*}{ Function } & Statement available & 39 \\
\cline { 2 - 3 } & Fully functional & $21(53.8)$ \\
\cline { 2 - 3 } & Mostly functional & $10(25.6)$ \\
\cline { 2 - 3 } & Improved & $2(5.1)$ \\
\cline { 2 - 3 } & Unclear information & $6(15.4)$ \\
\hline \multirow{5}{*}{ Surgery } & Statement available & $\mathbf{4 7}$ \\
\cline { 2 - 3 } & Not required & $39(83.0)$ \\
\cline { 2 - 3 } & Surgery performed & $3(10.6)$ \\
\cline { 2 - 3 } & No information & $3(6.4)$ \\
\hline
\end{tabular}

(e. g., fat, bone marrow), PRP and, as discussed here, ACS. Furthermore, combinations of surgical repair plus subsequent biological augmentation have been discussed in the literature [35]. In a casecontrol study of patients under 40 years of age, Pujol et al. [37] showed a moderate difference after 12 months between groups of open surgery meniscal repair with or without augmentation, in favor of PRP, using the Knee injury and Osteoarthritis Outcome Score (KOOS), the International Knee Documentation Committee (IKDC) Subjective Knee Evaluation Form and MRI. Griffin et al. [24] reported a case-control study of PRP-augmented and non-augmented arthroscopic meniscus surgery, with no significant differ- 
ence between the two groups at 24 months post-surgery. In this case, the main measurement instruments were IKDC and the Tegner-Lysholm score. In a randomized clinical trial, Vangsness et al. [42] compared injections of allograft mesenchymal stem cells (MSC; $50 \times 10^{6}$ cells vs. $150 \times 10^{6}$ cells vs. vehicle control) following partial medial meniscectomy. Using a visual analog scale, they showed intra-group symptomatic improvement and a statistically significant difference in pain between MSC groups and the control group at 24 months. The Tegner-Lysholm score improved significantly in all groups (17-19 patients in each), however no statistically significant differences were detected between groups. For a recent review of meniscus repair using MSC, see Yu et al. [45]; case reports of single cases have also been published [15], and a clinical trial combining surgical meniscus repair with PRP was announced in 2009, but aborted ahead of recruitment [11].

No final assessment has been reached regarding biological augmentation in meniscal repair; nevertheless, a biological approach is thought to have potential in this indication.

Results of an animal study indicated a significant clinical and histologic improvement in osteoarthritis-affected joints of horses following treatment with ACS, compared with placebo treatment [21]. A recent publication by de Girolamo et al. discussed the possible involvement of the blood/bone marrow-derived growth factor PDGF (platelet-derived growth factor; a major component of both PRP and ACS [43]) in improved meniscal healing associated with anterior cruciate ligament $(A C L)$ reconstruction surgery [13]. In vitro studies showed that growth factors including PDGF, TGFb1, IGF1, bFGF and EGF may play a beneficial role in meniscal cell or tissue development [39]. The standardized production and resulting composition of ACS have been described [43,44], however, to name one compound as the active component of ACS would be speculative; it is possible that there may be further known and unknown blood components involved, such as extracellular vesicles (exosomes) and their contents.

ACS is a complex mixture of biologically active signaling substances, with the preparation method optimized for anti-inflammatory and pain-reducing clinical action, which avoids some of the drawbacks associated with intra-articular PRP injections [43]. Published data show that platelets, as found in PRP, can exert strong pro-inflammatory effects in joints [9], such as complement activation [14] and release of Interleukin-1 (IL-1) [31, 41]. Plasma injections may lead to joint problems, resulting in intra-articular coagulation with associated complications, such as the necessity of clot removal by proteinases (e. g., plasmin) possibly damaging articular collagen [23]. Mice expressing an anticoagulant pro-thrombin protein are partially protected from collagen-induced arthritis. This supports the interpretation that clot formation in a joint, as seen with PRP injections, may have negative effects [20].

Elevated concentrations of biologically active - and potentially regenerative - components in cell-free ACS generated according to standard specifications have been reported [43]. Intra-articular ACS injections have been shown to be effective in OA $[8,22]$ and radicular pain [8]. Interestingly, ACS has also been described to have positive effects on tendon repair [33] and muscle healing [44]. ACS treatment success of knee OA may be independent of OA grade, age or BMI [5]. Taken together these results lend support to the hypothesis that augmentation of meniscus regeneration may be a clinical target for intra-articular injections of ACS.

In this retrospective data analysis, the improvement in symptoms shown by OKS correlates with a structural improvement in $49 \%$ of patients seen using the BLOKS MRI evaluation. There is a small but significant $(p<0.001)$ improvement in MRI-based meniscus morphology over all patients. Further examination should reveal a possible correlation with injury types more or less likely to respond. It remains to be shown in controlled studies if this effect can be reproduced and whether it is superior to other therapies. The OKS pain improvement is more pronounced than the OKS functional improvement. This is consistent with the WOMAC results from a previous study [5]. Regeneration of fibrous tissues such as tendons/ligaments is notoriously slow, and it is possible that to show on MRI regenerative/reparative effect caused by ACS requires longer than 6 months. Moreover, the possible effect of physiotherapy cannot be evaluated from this set of results and it should be considered that patients may prematurely return to their usual sports activities, due to their reduced pain, thereby jeopardizing tissue healing.

\section{Limitations}

This is an unblinded, uncontrolled retrospective case analysis with a small number of patients. The degree and type of meniscal lesions and the number of injections were not standardized, and the follow-up period was short (6 months). Such cohorts are representative of what is found in "real-world" practice and, since the mean OKS improvements are much higher than the MCID of 5.0, controlled studies are justified to validate these findings. Additionally, studies are recommended to determine if postsurgical ACS may improve healing of complex meniscal tears following arthroscopic meniscal repair.

Due to the lack of a control group in this retrospective case analysis of routine patients, the possibility of a placebo effect contributing to the results needs to be acknowledged. Osteoarthritis injection therapy studies have demonstrated that a placebo effect could contribute to approximately $20-30 \%$ of parameter improvement [6], whereas in this study, OKS score improvements range from $29-38 \%$, so there is reasonable evidence that the improvement is most likely not simply due to a placebo effect.

\section{Conclusion}

The data presented here are derived from a retrospective analysis of an uncontrolled case series. The mean magnitude of OKS improvement in this study is $\sim 15$ points, higher than the minimally detectable difference (MID) of 4.15 points previously published [7], but comparable to that reported by Clement et al. [10]. Although spontaneous healing can occur in meniscal injuries, an effect of the magnitude like the one reported here is most likely not attributable to a spontaneous process, and the prevention of surgery in the majority of patients ( $83 \%$ ) during 6 months of follow-up is meaningful.

A randomized, controlled clinical study is required to generate further evidence for the ability of ACS to contribute to meniscal repair; however, this retrospective cohort study implies that intraarticular ACS injection may be an effective treatment option for knee pain associated with meniscal lesions. 


\section{Conflict of Interest}

The author declares no conflict of interest.

\section{References}

[1] Freiburger Ethik-Kommission International (FEKI). Available at http:// www.ethicscommission.com/ Accessed June 2017

[2] Oxford Knee Score. Available at: http://www.orthopaedicscore.com/ scorepages/oxford_knee_score.html Accessed July 2017

[3] Oxford University Innovation: The Oxford Knee Score (OKS) and Oxford Knee Score-Activity \& Participation Questionnaire (OKSAPQ).Available at https://innovation.ox.ac.uk/outcome-measures/ oxford-knee-score-activity-participation-questionnaire-oks-apq/ 2015; Accessed July 2017

[4] VIP Check International. Available at: http://vipcheck.org Accessed June 2017

[5] Baltzer A, Moser C, Jansen S, Krauspe R. Autologous conditioned serum (Orthokine) is an effective treatment for knee osteoarthritis. Osteoarthritis Cartilage 2009; 17: 152-160

[6] Bannuru RR, Schmid CH, Kent DM, Vaysbrot EE, Wong JB, McAlindon TE. Comparative effectiveness of pharmacologic interventions for knee osteoarthritis: A systematic review and network meta-analysis. Ann Intern Med 2015; 162: 46-54

[7] Beard DJ, Harris K, Dawson J, Doll H, Murray DW, Carr AJ, Price AJ. Meaningful changes for the Oxford hip and knee scores after joint replacement surgery. J Clin Epidemiol 2015; 68: 73-79

[8] Becker C, Heidersdorf S, Drewlo S, de Rodriguez SZ, Krämer J, Willburger RE. Efficacy of epidural perineural injections with autologous conditioned serum for lumbar radicular compression: an investigator-initiated, prospective, double-blind, reference-controlled study. Spine (Phila Pa 1976) 2007; 32: 1803-1808

[9] Boilard E, Nigrovic PA, Larabee K, Watts GF, Coblyn JS, Weinblatt ME, Massarotti EM, Remold-O’Donnell E, Farndale RW, Ware J. Platelets amplify inflammation in arthritis via collagen-dependent microparticle production. Science 2010; 327: 580-583

[10] Clement N, MacDonald D, Simpson A. The minimal clinically important difference in the Oxford knee score and Short Form 12 score after total knee arthroplasty. Knee Surg. Sports Traumatol. Arthrosc 2014; 22: 1933-1939

[11] ClinicalTrials.gov. Assessment of outcome of meniscus repair with or without platelet rich plasma: NCT00961597. 2014. Available at: https://clinicaltrials.gov/ct2/show/study/NCT00961597 Accessed September 2016

[12] Cohen J. A power primer. Psychol Bull 1992; 112: 155

[13] de Girolamo L, Galliera E, Volpi P, Denti M, Dogliotti G, Quaglia A, Cabitza P, Romanelli MC, Randelli P. Why menisci show higher healing rate when repaired during $A C L$ reconstruction? Growth factors release can be the explanation. Knee Surg Sports Traumatol Arthrosc 2015 23: 90-96

[14] del Conde I, Crúz MA, Zhang H, López JA, Afshar-Kharghan V. Platelet activation leads to activation and propagation of the complement system. J Exp Med 2005; 201: 871-879

[15] Delos D, Rodeo SA. Enhancing meniscal repair through biology: Platelet-rich plasma as an alternative strategy. Instr Course Lect 2010 60: 453-460

[16] Englund M, Guermazi A, Gale D, Hunter DJ, Aliabadi P, Clancy M, Felson DT. Incidental meniscal findings on knee MRI in middle-aged and elderly persons. N Engl J Med 2008; 359: 1108-1115
[17] Englund M, Roos E, Lohmander L. Impact of type of meniscal tear on radiographic and symptomatic knee osteoarthritis: A sixteen-year followup of meniscectomy with matched controls. Arthritis Rheum. 2003; 48: 2178-2187

[18] Evans CH, Chevalier X, Wehling P. Autologous Conditioned Serum. Phys Med Rehabil Clin N Am 2016; 27: 893-908

[19] Felson DT, Lynch J, Guermazi A, Roemer FW, Niu J, McAlindon T, Nevitt MC. Comparison of BLOKS and WORMS scoring systems part II. Longitudinal assessment of knee MRIs for osteoarthritis and suggested approach based on their performance: Data from the Osteoarthritis Initiative. Osteoarthritis Cartilage 2010; 18: 1402-1407

[20] Flick M], Chauhan AK, Frederick M, Talmage KE, Kombrinck KW, Miller W, Mullins ES, Palumbo JS, Zheng X, Esmon NL. The development of inflammatory joint disease is attenuated in mice expressing the anticoagulant prothrombin mutant W215A/E217A. Blood 2011; 117: 6326-6337

[21] Frisbie DD, Kawcak CE, Werpy NM, Park RD, Mcllwraith CW. Clinical, biochemical, and histologic effects of intra-articular administration of autologous conditioned serum in horses with experimentally induced osteoarthritis. Am J Vet Res 2007; 68: 290-296

[22] García-Escudero JB. Trillos PMH. Treatment of osteoarthritis of the knee with a combination of autologous conditioned serum and physiotherapy: A two-year observational study. PLoS One 2015; 10: e0145551

[23] Goldring SR, Scanzello CR. Plasma proteins take their toll on the joint in osteoarthritis. Arthritis Res Ther 2012; 14: 111

[24] Griffin JW, Hadeed MM, Werner BC, Diduch DR, Carson EW, Miller MD. Platelet-rich plasma in meniscal repair: Does augmentation improve surgical outcomes? Clin Orthop Relat Res 2015; 473: 1665-1672

[25] Harriss DJ, Atkinson G. Ethical standards in sport and exercise science research: 2016 update. Int ] Sports Med 2015; 36: 1121-1124

[26] Hunter D, Zhang Y, Niu J, Tu X, Amin S, Clancy M, Guermazi A, Grigorian M, Gale D, Felson D. The association of meniscal pathologic changes with cartilage loss in symptomatic knee osteoarthritis. Arthritis Rheum 2006; 54: 795-801

[27] Katz JN, Brophy RH, Chaisson CE, De Chaves L, Cole B], Dahm DL, Donnell-Fink LA, Guermazi A, Haas AK, Jones MH. Surgery versus physical therapy for a meniscal tear and osteoarthritis. N Engl J Med 2013; 368: 1675-1684

[28] Khan M, Evaniew N, Bedi A, Ayeni OR, Bhandari M. Arthroscopic surgery for degenerative tears of the meniscus: A systematic review and meta-analysis. Can Med Assoc J 2014; 186: 1057-1064

[29] Kirkley A, Birmingham TB, Litchfield RB, Giffin JR, Willits KR, Wong C], Feagan BG, Donner A, Griffin SH, D'Ascanio LM. A randomized trial of arthroscopic surgery for osteoarthritis of the knee. N. Engl. J. Med 2008; 359: 1097-1107

[30] LaPrade RF, Burnett QM, Veenstra MA, Hodgman CG. The prevalence of abnormal magnetic resonance imaging findings in asymptomatic knees with correlation of magnetic resonance imaging to arthroscopic findings in symptomatic knees. Am J Sports Med 1994; 22: 739-745

[31] Lindemann S, Tolley ND, Dixon DA, Mclntyre TM, Prescott SM, Zimmerman GA, Weyrich AS. Activated platelets mediate inflammatory signaling by regulated interleukin $1 \beta$ synthesis. J Cell Biol 2001; 154: 485-490

[32] Lynch JA, Roemer FW, Nevitt MC, Felson DT, Niu J, Eaton CB, Guermazi A. Comparison of BLOKS and WORMS scoring systems part I. Cross sectional comparison of methods to assess cartilage morphology, meniscal damage and bone marrow lesions on knee MRI: data from the osteoarthritis initiative. Osteoarthritis Cartilage 2010; 18: 1393-1401

[33] Majewski M, Ochsner PE, Liu F, Flückiger R, Evans CH. Accelerated healing of the rat Achilles tendon in response to autologous conditioned serum. Am J Sports Med 2009; 37: 2117-2125 
[34] McAlindon T, Bannuru RR, Sullivan M, Arden N, Berenbaum F, Bierma-Zeinstra S, Hawker G, Henrotin Y, Hunter D, Kawaguchi H. OARSI guidelines for the non-surgical management of knee osteoarthritis. Osteoarthritis Cartilage 2014; 22: 363-388

[35] Moran C], Busilacchi A, Lee CA, Athanasiou KA, Verdonk PC. Biological augmentation and tissue engineering approaches in meniscus surgery. Arthroscopy 2015; 31: 944-955

[36] Moseley JB, O'Malley K, Petersen NJ, Menke TJ, Brody BA, Kuykendall $\mathrm{DH}$, Hollingsworth JC, Ashton CM, Wray NP. A controlled trial of arthroscopic surgery for osteoarthritis of the knee. N Engl J Med 2002; 347: $81-88$

[37] Pujol N, De Chou ES, Boisrenoult P, Beaufils P. Platelet-rich plasma for open meniscal repair in young patients: Any benefit? Knee Surg Sports Traumatol Arthrosc 2015; 23: 51-58

[38] Shelbourne KD, Heinrich J. The long-term evaluation of lateral meniscus tears left in situ at the time of anterior cruciate ligament reconstruction. Arthroscopy 2004; 20: 346-351

[39] Stewart K, Pabbruwe M, Dickinson S, Sims T, Hollander AP, Chaudhuri JB. The effect of growth factor treatment on meniscal chondrocyte proliferation and differentiation on polyglycolic acid scaffolds. Tissue Eng 2007; 13: 271-280
[40] Thorlund JB, Juhl CB, Roos EM, Lohmander L. Arthroscopic surgery for degenerative knee: systematic review and meta-analysis of benefits and harms. Br Med J 2015; 350: h2747

[41] Thornton P, McColl BW, Greenhalgh A, Denes A, Allan SM, Rothwell NJ. Platelet interleukin- $1 \alpha$ drives cerebrovascular inflammation. Blood 2010; 115: 3632-3639

[42] Vangsness CT, Farr J, Boyd J, Dellaero DT, Mills CR, LeRoux-Williams M. Adult human mesenchymal stem cells delivered via intra-articular injection to the knee following partial medial meniscectomy. J Bone Joint Surg Am 2014; 96: 90-98

[43] Wehling P, Moser C, Frisbie D, Mcllwraith CW, Kawcak CE, Krauspe R, Reinecke JA. Autologous conditioned serum in the treatment of orthopedic diseases: the orthokine therapy. BioDrugs 2007; 21: 323-332

[44] Wright-Carpenter T, Klein P, Schaferhoff P, Appell H, Mir L, Wehling P. Treatment of muscle injuries by local administration of autologous conditioned serum: A pilot study on sportsmen with muscle strains. Int J Sports Med 2004; 25: 588-593

[45] Yu H, Adesida AB, Jomha NM. Meniscus repair using mesenchymal stem cells-a comprehensive review. Stem Cell Res Ther 2015; 6: 86 